\title{
Actual pentamidine dose delivered by Respigard II nebulizer
}

\author{
C.S. Kim, L.Garcia, A. Wanner
}

Actual pentamidine dose delivered by Respigard II nebulizer. C.S. Kim, L.Garcia, A. Wanner. C)ERS Journals Ltd 1995.

ABSTRACT: The Respigard II nebulizer system is the approved method to deliver pentamidine aerosols in the USA. Although continuous operation of the nebulizer until dryness is a designated regimen, the actual pentamidine dose delivered under the operating condition has not been thoroughly studied.

Pentamidine solutions (300 mg in $6 \mathrm{~mL}$ water) were nebulized continuously with the Respigard II nebulizer system until dryness (40 min operation). Aerosols were delivered to the lower airways via an oropharyngeal model and sampled on a filter with a standard breathing mode of 20 breaths $\cdot \mathrm{min}^{-1}$ frequency and $750 \mathrm{~mL}$ tidal volume. Intermediate samples were also obtained for the initial 20 min delivery.

The pentamidine dose delivered to the mouth was $1.6 \%$ of the dose placed in the nebulizer. Of the dose delivered to the mouth, $92 \%$ was delivered during the initial 20 min period. Aerosol loss in the oropharyngeal model was $15 \%$ of the dose delivered to the mouth or $0.24 \%$ of the dose initially placed in the nebulizer.

Pentamidine dose delivered to the lower airways was a very small fraction of the initial dose in the nebulizer. A partial delivery for the initial 20 min was nearly comparable to complete delivery.

Eur Respir J., 1995, 8, 2178-2181.
Pulmonary Division, University of Miami school of Medicine, Mount Sinai Medical Center, Miami Beach, Florida, USA.

Correspondence: C.S. Kim

Human Studies Division (MD-58)

National Health and Environmental

Effects Research Laboratory

U.S. Environmental Protection Agency

Research Triangle Park

NC 27711

USA

Keywords: Aerosol delivery

nebulizer

pentamidine

Received: September 301994

Accepted after revision July 121995
Aerosolized pentamidine is frequently used for the treatment of Pneumocystis carinii pneumonia (PCP) in patients with the acquired immune deficiency syndrome (AIDS) $[1,2]$. Recent studies have also shown that pentamidine aerosol is effective for the prophylaxis of PCP [3], and it is commonly used for this purpose. However, precise dosage control is often difficult in aerosol therapy. The drug dose delivered to the lung is usually much lower than the dose placed in the nebulizer, and varies widely depending on the types and operational conditions of nebulizers. In order to assure a consistent drug delivery, the Federal Drug Administration (FDA) has approved prophylactic use of pentamidine aerosol (300 mg dose every 4 weeks) with a regimen specific to the Respigard II nebulizer (RPG II, Marquest, CO, USA) [3]. The RPG II system has been shown to deliver more pentamidine to the human lung than intravenous injection [4], and has been used successfully in the treatment of AIDS patients with PCP [1-3]. However, the absolute drug dose delivered and the variability of the amount of drug delivered have not been fully documented. The lack of information on aerosol delivery makes it difficult to estimate the actual therapeutic dose of pentamidine aerosol and to compare the current regimen with other alternatives.

SMALDONE et al. [5] compared delivery of pentamidine aerosolized with three different nebulizer systems, including the RPG II. The RPG II was found to be least efficient among those tested, delivering only a few percent of the drug mass placed in the nebulizer. The RPG II, however, was tested only for the initial 20 min delivery and a substantial amount of solution was left unused in the nebulizer. This differs from the FDA guideline that recommends a complete nebulization until the chamber is empty. In recent studies [6], delivery of pentamidine from the RPG II was measured as a function of time until dryness. Operation of the nebulizer, however, was interrupted every $5 \mathrm{~min}$ to collect samples, which could alter the delivery characteristics of the nebulizer.

The purpose of the present study was to determine the delivered dose of pentamidine aerosol with continuous operation of the nebulizer until dryness. Delivered dose was measured with and without an oropharyngeal model to investigate the influence of the upper airways. The results of the present study may supplement the previous results and may be used as the basis of comparing different delivery systems and of interpreting the therapeutic effect of pentamidine aerosol.

\section{Materials and methods}

\section{Respigard II nebulizer system (RPG II)}

The system consists of an air jet nebulizer, a Y-piece with two one-way valves installed at the inspiratory and expiratory limbs, an expiratory filter, and a mouthpiece (fig. 1). The nebulizer is connected to the side of the inspiratory limb of the Y-piece via a T-connector. A short corrugated hose and a one-way valve are attached to the inlet port of the T-connector. During operation, aerosols are generated continuously with compressed air at $7.25 \mathrm{kPa}$, at which a jet airflow rate of $6 \mathrm{~L} \cdot \mathrm{min}^{-1}$ is 


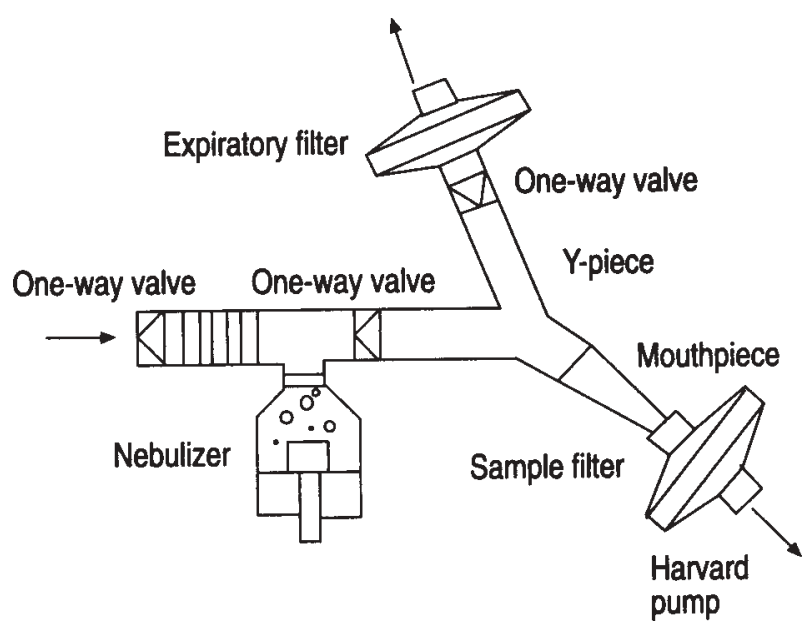

Fig. 1. - Experimental set-up for measuring dose of pentamidine aerosol delivered by the Respigard II nebulizer system.

achieved in the nebulizer. Aerosol is inhaled along with room air drawn through the inspiratory valves and exhausted through the expiratory filter.

\section{Experimental procedure}

A $300 \mathrm{mg}$ dose of pentamidine isethionate (NebuPent ${ }^{\mathbb{T W}}$, Lyphomed, Rosemont, IL, USA) was dissolved in $6 \mathrm{~mL}$ distilled water, and the entire solution was poured into the RPG II nebulizer chamber. The nebulizer was operated continuously with compressed air at $7.25 \mathrm{kPa}$ (6 L. $\mathrm{min}^{-1}$ jet airflow rate) for $20 \mathrm{~min}$, while output aerosol was drawn through a $47 \mathrm{~mm}$ diameter high efficiency particulate air (HEPA) glass fibre filter (Type A/E, Gelman Laboratories, Ann Arbor, MI, USA) connected tightly to the mouthpiece. A Harvard respirator pump was used to draw the aerosol through the filter. The inlet of the pump was connected to the filter and the outlet of the pump was connected to the exhaust. Because the pump was equipped with a one-way poppet valve at the inlet and outlet port, aerosol was drawn through the filter only during the inspiratory phase and there was no flow through the filter during the expiratory phase. The pump was operated with a standardized breathing pattern of 20 breaths $\cdot \mathrm{min}^{-1}$ and $750 \mathrm{~mL}$ tidal volume. Time for inspiratory and expiratory phase was the same. After the initial 20 min sampling, the filter was replaced with a new filter and sampling was continued for another $20 \mathrm{~min}$ : at the end of the sampling the nebulizer was completely empty. Each of the two 20 min sample filters and a clean unused filter as a reference were immersed in $20 \mathrm{~mL}$ of distilled water and sonicated for $1 \mathrm{~min}$. The solution was then analysed for pentamidine content by UV spectrophotometry at a wavelength of $260 \mathrm{~nm}$ (Lambda 3B, Perkin-Elmer Co.). Prior to use, the spectrophotometer was calibrated with solutions of known concentrations of pentamidine. All the samples analysed were diluted to the linear range of the calibration curve. The initial solutions placed in the nebulizer were also analyzed for pentamidine before nebulization.

To estimate aerosol deposition in the upper airways, the same experiments were repeated with an oropharyngeal (OP) model interposed between the mouthpiece and filter. The oropharyngeal model was made with glass according to the anatomical dimensions of a human adult, and was previously used to estimate oropharyngeal deposition of aerosols from metered-dose inhalers [7]. The oropharyngeal model had a uvula at the entrance to the pharynx; the distance from the opening of the mouth to the back of the pharynx was $10 \mathrm{~cm}$ and the volume of the mouth cavity was about $90 \mathrm{~mL}$. After sampling, the OP model was filled with $60 \mathrm{~mL}$ water, both the entrance and exit of the model were sealed with parafilm, and the model was shaken gently for $60 \mathrm{~s}$ to dissolve deposited pentamidine. The same nebulizer was used for the entire study.

Table 1. - Pentamidine aerosol delivered to the mouth and lower airways by the Respigard II nebulizer system

\begin{tabular}{|c|c|c|c|c|c|}
\hline & $\begin{array}{l}\text { Initial dose } \\
\text { mg }\end{array}$ & $\begin{array}{l}1 \text { st } 20 \mathrm{~min} \\
\mathrm{mg}\end{array}$ & $\begin{array}{c}\text { 2nd } 20 \mathrm{~min} \\
\mathrm{mg}\end{array}$ & $\begin{array}{c}\text { Total } \\
\text { mg }\end{array}$ & $\begin{array}{l}\% \text { total } \\
\text { delivery }\end{array}$ \\
\hline $\begin{array}{l}\text { Dose delivered } \\
\text { to the mouth }\end{array}$ & $\begin{array}{l}260 \\
255 \\
252 \\
270 \\
258\end{array}$ & $\begin{array}{ll}3.90 & (90)^{+} \\
3.45 & (91) \\
3.55 & (95) \\
4.18 & (93) \\
3.77 & (92)\end{array}$ & $\begin{array}{l}0.45 \\
0.33 \\
0.21 \\
0.29 \\
0.33\end{array}$ & $\begin{array}{l}4.35 \\
3.78 \\
3.75 \\
4.47 \\
4.10\end{array}$ & $\begin{array}{l}1.7 \\
1.5 \\
1.5 \\
1.7 \\
1.6\end{array}$ \\
\hline $\begin{array}{l}\text { Mean } \\
\pm \text { SD }\end{array}$ & $\begin{array}{r}259 \\
8\end{array}$ & $\begin{array}{ll}3.77 & (92) \\
0.29 & (2)\end{array}$ & $\begin{array}{l}0.32 \\
0.09\end{array}$ & $\begin{array}{l}4.09 \\
0.32\end{array}$ & $\begin{array}{l}1.6 \\
0.1\end{array}$ \\
\hline $\begin{array}{l}\text { Delivered dose to } \\
\text { the lowered airways }\end{array}$ & $\begin{array}{l}252 \\
270 \\
258\end{array}$ & $\begin{array}{l}3.03 \\
3.55 \\
3.19\end{array}$ & $\begin{array}{l}0.17 \\
0.25 \\
0.28\end{array}$ & $\begin{array}{l}3.20 \\
3.79 \\
3.47\end{array}$ & $\begin{array}{l}1.3 \\
1.4 \\
1.3\end{array}$ \\
\hline $\begin{array}{l}\text { Mean } \\
\pm \text { SD }\end{array}$ & $\begin{array}{r}260 \\
9\end{array}$ & $\begin{array}{l}3.26 \\
0.27\end{array}$ & $\begin{array}{l}0.23 \\
0.05\end{array}$ & $\begin{array}{l}3.49 \\
0.30\end{array}$ & $\begin{array}{l}1.3 \\
0.1\end{array}$ \\
\hline $\begin{array}{l}\text { Deposition in the } \\
\text { oropharyngeal model }\end{array}$ & $\begin{array}{l}252 \\
270 \\
258\end{array}$ & $\begin{array}{l}0.52 \\
0.64 \\
0.58\end{array}$ & $\begin{array}{l}0.03 \\
0.04 \\
0.05\end{array}$ & $\begin{array}{l}0.55 \\
0.68 \\
0.64\end{array}$ & $\begin{array}{l}0.21 \\
0.25 \\
0.25\end{array}$ \\
\hline $\begin{array}{l}\text { Mean } \\
\pm \mathrm{SD}\end{array}$ & $\begin{array}{r}260 \\
9\end{array}$ & $\begin{array}{l}0.58 \\
0.06\end{array}$ & $\begin{array}{l}0.04 \\
0.01\end{array}$ & $\begin{array}{l}0.62 \\
0.06\end{array}$ & $\begin{array}{l}0.24 \\
0.02\end{array}$ \\
\hline
\end{tabular}

$*$ : total dose delivered/initial dose $\times 100 ;{ }^{+}: \%$ contribution to total mouth delivery $(1$ st 20 min dose/total dose delivered $\times 100)$. 
Delivery efficiency of pentamidine to the mouth was calculated from the ratio of the pentamidine mass collected on the filter at the outlet of the mouthpiece to the total pentamidine initially placed in the nebulizer. Delivery efficiency to the lower airways was determined similarly on the basis of pentamidine mass collected on the filter at the outlet of the OP model.

\section{Results}

Total pentamidine dose in the solution placed in the nebulizer was $259 \pm 8$ (mean \pm SD) $\mathrm{mg}$ (range 252$270 \mathrm{mg}$ ). Pentamidine dose delivered to the mouth was $3.77 \pm 0.29 \mathrm{mg}$ during the first $20 \mathrm{~min}$, and an additional $0.32 \pm 0.09 \mathrm{mg}$ was delivered during the second $20 \mathrm{~min}$. Therefore, the total dose delivered was $4.09 \pm 0.32 \mathrm{mg}$ : this was $1.6( \pm 0.1) \%$ (range $1.5-1.7 \%)$ of the dose initially placed in the nebulizer. During the first $20 \mathrm{~min}, 92 \%$ of the total delivery was made. Of the dose delivered to the mouth, $15 \%(0.62 \pm 0.06 \mathrm{mg})$ was deposited in the OP model and the rest $(3.49 \pm 0.3 \mathrm{mg})$ was delivered past the model (table 1).

\section{Discussion}

The results of the present study demonstrate that the dose of pentamidine delivered by the Respigard II nebulizer system is extremely low. A complete nebulization until dryness increased the delivered dose only marginally when compared with a partial nebulization that occurred during the first 20 min under the operating conditions used. Our results also show that the in vitro testing method using filter sampling is simple and consistent, and suggest that the method may be used for evaluation of delivery systems and for comparing delivery characteristics of different nebulizer and/or inhaler systems.

Our results show that the dose delivered to the mouth by the RPG II is $1.6 \%$ of the dose initially charged in the nebulizer. Using a similar experimental set-up, SMALDONE and co-workers [5] showed delivery of 3-6\% for the initial $20 \mathrm{~min}$ period; these values could have been slightly higher if the delivery had been continued until the nebulizer chamber was empty. In a subsequent study SMALDONE and co-workers [6] reported a delivery of $12 \%$ with complete nebulization. The smaller delivery in our study may be attributed, in part, to differences in the experimental methods employed including operating conditions of the nebulizer, type of filters and drug assay, among others. SMALDONE and co-workers [6] interrupted the operation of their nebulizer every $5 \mathrm{~min}$ to replace sample filters, possibly allowing accumulation of solution that was spread over the inner surface of the nebulizer chamber, which was then nebulized when operation was started again. On the other hand, the present results may be a slight underestimation because extraction efficiency of pentamidine from filter samples was found to be $85 \%$ $(\mathrm{SD}=7 ; \mathrm{n}=6)$. The extraction efficiency was obtained by collecting pentamidine aerosols of known dose $(250 \mu \mathrm{g})$ from a specially prepared metered-dose canister. Nonetheless, both studies show very low delivery efficiencies of the RPG II system and the difference may not be of any practical significance.

The reason for the low efficiency can be attributed mainly to three factors: residual solution volume in the nebulizer; expiratory loss; and deposition in the one-way valve. It should be noted that not all of the solution volume placed in the nebulizer can be nebulized. In commonly used disposable nebulizers, $1-2 \mathrm{~mL}$ of solution remains in the nebulizer as drops and films on the inner surface of the chamber at the end of nebulization $[8,9]$. This results in a significant decrease in aerosol delivery from the nebulizer, particularly if a small volume of solution is to be nebulized. The decrease in delivery is expected to be even greater if solutions are viscous because viscous liquids can remain as a thicker film on the chamber surface [9]. With the RPG II system, it has previously been reported that half of the initial drug dose was trapped in the nebulizer at the end of operation $[1,2]$; and only $50 \%$ of the initial drug dose could be discharged from the nebulizer. Of the aerosols discharged from the nebulizer, a half could have been exhausted during expiration, because time for inspiration and expiration was the same in our experiment. AHMED et al. [8] have shown that a one-way poppet valve could cause as much as 50\% aerosol loss during a normal breathing cycle. Therefore, an additional 50\% loss could have occurred in the one-way valve interposed between the nebulizer and mouthpiece during inspiration, resulting in a delivery efficiency of about $12 \%(0.5 \times 0.5 \times 0.5)$. Because deposition of aerosols in the Y-tube and mouthpiece could contribute to a further decline of the efficiency, our results of $1.6 \%$ efficiency are in a general agreement with this simplistic estimation. It should be noted that, in reality, the expiratory loss would be greater than the estimated value of 50\% because expiratory time is usually longer than inspiratory time in normal breathing. Furthermore, because aerosols are continuously nebulized, any loss of breaths during a long inhalation time will result in an additional loss of aerosols.

However, an improvement of delivery efficiency might be achieved by removing the one-way valve placed in the inspiratory limb of the Y-piece. The valve may not be necessary because the system has an additional oneway valve at the inlet of the inspiratory limb (see fig. 1). A high delivery dose shown with other nebulizer systems [5], i.e. Aerotech II and Fisoneb, can be attributed partly to the fact that the systems do not have any valves between the nebulizer and mouthpiece. An intermittent nebulization in phase with inspiration may eliminate the expiratory loss of aerosol and increase the delivery efficiency.

Particle size of pentamidine aerosol at the mouthpiece of the RPG II system was found to be about $0.8 \mu \mathrm{m}$ in mass median aerodynamic diameter in one study [1, 5] and $1.4 \mu \mathrm{m}$ in another [2]. In this size range, 10-20\% of inhaled particles are expected to deposit in the healthy lung during normal breathing [10]. However, lung deposition usually increases in patients with airway 
disease: a consistent increase in lung deposition has been demonstrated both in animals with induced airway obstructions [11], and patients with chronic obstructive airway disease [12]. SMALDONE and co-workers [6] showed that about $62 \%$ of the inhaled pentamidine was deposited in the lungs of AIDS patients whose lungs were diagnosed to have restrictive lung disease. Pentamidine dose deposited in the lungs of these patients was $12-13 \mathrm{mg}$ when $600 \mathrm{mg}$ pentamidine was delivered by the RPG II nebulizer system; lung deposition efficiency of pentamidine aerosol was about $2 \%$. Using these in vivo deposition data, the present in vitro test results suggest that pentamidine dose deposited in AIDS patients may be estimated to be in the vicinity of $1 \%$ (i.e. $1.6 \% \times 0.62)$ of the initial dose in a nebulizer, the value consistent with in vivo results.

The oropharyngeal model used in the present study has shape and dimensions similar to an adult oropharyngeal cavity, and has been used to test metered-dose inhalers [7]. The model may not represent all true clinical situations but may be considered to be a fair representation of a typical situation. Oropharyngeal deposition of nebulizer aerosols in humans has been variously reported as $2-15 \%$, and often presented in different data forms, i.e. as a percentage of total deposition in the respiratory tract or as a percent of total dose delivered from the nebulizers used [13-15]. Because of varying experimental conditions, conversion of these data into a common expression, i.e. percentage of the dose delivered to the mouth, is not warranted. Under the existing circumstances, the present results, $15 \%$ of the dose delivered to the mouth or $0.24 \%$ of the dose initially placed in the nebulizer, may be viewed to be in a general agreement with the reported in vivo results.

The RPG II nebulizer was designed to generate fine aerosols that are suitable for alveolar delivery. However, because the fine aerosols are generated by selectively removing large size droplets by means of an impaction baffle (the removed droplets flowing back to the solution chamber), it was to be expected that the rate of aerosol mass output from the nebulizer would be low and the time for a complete nebulization would be long. Our results showing a long nebulization time (i.e. $40 \mathrm{~min}$ ) compared with a nebulization time of 10-15 min for other commonly used medical nebulizers are, therefore, consistent with these expectations. In practice, a long nebulization time may not be desired because the patients' compliance deteriorates when the nebulization time is too long, i.e. $>10-15$ min [9]. However, because about $92 \%$ of total drug delivery can be achieved during the initial $20 \mathrm{~min}$ period, as shown in the present results, the RPG II system may be used with a reduced nebulization time +of $20 \mathrm{~min}$ with no practical difference in aerosol delivery dose compared to a $40 \mathrm{~min}$ complete nebulization. This indeed supports the new 20 min National Institutes of Health (NIH) nebulization protocol used by SMALDONE and co-workers [5].

The implications of the results are that aerosol delivery by RPG II nebulizer system is very low and variable with mode of operation. However, because the RPG II system has been shown to be effective for pentamidine therapy in clinical trials [1-3], this suggests that therapeutic dose of pentamidine may be very low, as indicated by in vitro testings. An improved delivery system could then deliver the effective therapeutic dose of pentamidine with a short delivery time and/or with solutions of low drug concentrations. In order to estimate the actual delivery of aerosol in clinical situations and/or to evaluate different delivery systems, use of an appropriate in vitro testing system would be valuable.

\section{References}

1. Miller RF, Godfrey-Fausset P, Semple SJG. Nebulized pentamidine as treatment for pnemocyctis carinii pneumonia in the acquired immunodeficiency syndrome. Thorax 1989 ; 44: 565-569.

2. Montgomery AB, Luce JM, Turner J, et al. Aerosolized pentamidine as sole therapy for Pneumocystis carinii pneumonia in patients with acquired immunodeficiency syndrome. Lancet 1987; ii: 480-483.

3. Public Health Service Task Force Recommendations. Anti-pneumocystis prophylaxis for patients infected with human immunodeficiency virus. Aids Patient Care 1990; April: 5-14.

4. Montgomery AB, Debs RJ, Luce JM, et al. Selective delivery of pentamidine to the lung by aerosol. Am Rev Respir Dis 1988; 137: 477-478.

5. Smaldone GC, Perry RJ, Deutch DG. Characteristics of nebulizers used in the treatment of AIDS-related pneumocystis carinii pneumonia. J Aerosol Med 1988; 1: 113-126.

6. Smaldone GC, Fuhrer J, Steigbigel RT, McPeck M. Factors determining pulmonary deposition of acrosolized pentamidine in patients with human immunodeficiency virus infection. Am Rev Respir Dis 1991; 143: 727-737.

7. Kim CS, Eldridge MA, Sackner MA. Oropharyngeal deposition and delivery aspect of metered-dose inhaler aerosols. Am Rev Respir Dis 1987; 135: 157-164.

8. Ahmed T, Russi E, Kim CS, Ignatio D. Comparative effects of oral and inhaled verapamil on antigen-induced bronchoconstriction. Chest 1986; 88: 176-180.

9. Newman SP, Pellow PGD, Clay MM, Clarke SW. Evaluation of jet nebulizer for use with gentamicin solution. Thorax 1985; 40: 671-676.

10. Heyder J, Gebhart J, Rudolf G, Schiller CF, Stahlhofen W. Deposition of particles in the human respiratory tract in the size range 0.005-15 $\mu \mathrm{m}$. J Aerosol Sci 1986; 17: 811-825.

11. Kim CS. Aerosol deposition in the lung with obstructed airways. J Aerosol Med 1989; 2: 111-120.

12. Kim CS, Lewars GA, Sackner MA. Measurement of total lung aerosol deposition as an index of lung abnormality. $J$ Appl Physiol 1988; 64: 1527-1536.

13. Clay MM and Clarke SW. Effect of nebulized aerosol size on lung deposition in patients with mild asthma. Thorax 1987; 42: 190-194.

14. Lewis RA, Fleming JS. Fractional deposition from a jet nebulizer: how it differs from a metered-dose inhaler. Br J Dis Chest 1985; 79: 361-367.

15. Macintyre NR, SilverRM, MillerCW,SchulerF, ColemanRE. Aerosol delivery in intubated, mechanically-ventilated patients. Crit Care Med 1985; 13: 81-84. 